Corrigendum

\title{
Corrigendum to "Prediction of Endometrial Hyperplasia and Cancer among Premenopausal Women with Abnormal Uterine Bleeding"
}

\author{
Luca Giannella $\mathbb{D}^{1},{ }^{1}$ Lillo Bruno Cerami, ${ }^{1}$ Tiziano Setti, ${ }^{1}$ Ezio Bergamini, ${ }^{1}$ and Fausto Boselli ${ }^{2}$ \\ ${ }^{1}$ Azienda USL-IRCCS di Reggio Emilia, Italy \\ ${ }^{2}$ Mother-Infant Department, Institute of Obstetrics and Gynecology, University of Modena and Reggio Emilia, Modena, Italy \\ Correspondence should be addressed to Luca Giannella; lucazeta1976@libero.it \\ Received 20 April 2020; Accepted 21 April 2020; Published 28 May 2020 \\ Copyright ( 2020 Luca Giannella et al. This is an open access article distributed under the Creative Commons Attribution License, \\ which permits unrestricted use, distribution, and reproduction in any medium, provided the original work is properly cited.
}

In the article titled "Prediction of Endometrial Hyperplasia and Cancer among Premenopausal Women with Abnormal Uterine Bleeding" [1], authors Luca Giannella, Lillo Bruno Cerami, Tiziano Setti, and Ezio Bergamini were affiliated to the Local Health Authority of Reggio Emilia-IRCCS, Obstetrics and Gynecology Unit, Cesare Magati Hospital, Scandiano, Italy, which is incorrect. The correct affiliation for these authors is shown above.

\section{References}

[1] L. Giannella, L. B. Cerami, T. Setti, E. Bergamini, and F. Boselli, "Prediction of endometrial hyperplasia and cancer among premenopausal women with abnormal uterine bleeding," BioMed Research International, vol. 2019, Article ID 8598152, 6 pages, 2019. 